\title{
CREEP AND FATIGUE PROPERTIES OF A DIRECTIONALLY SOLIDIFIED NICKEL BASE SUPERALLOY AT ELEVATED TEMPERATURE
}

\author{
M. Maldini ${ }^{(*)}$, M. Marchionni ${ }^{(*)}$, M.Nazmy $^{(0)}$, M. Staubli ${ }^{\left({ }^{\circ}\right)}$ and G. Osinkolu ${ }^{(*)}$ \\ (") CNR-ITM, Cinisello B. (Milano), Italy \\ (o) ABB Power Generation, Baden, Switzerland
}

\begin{abstract}
$\underline{\text { Abstract }}$
The creep and fatigue properties of the directionally solidified nickel base superalloy CM247LC DS have been investigated. Constant creep tests have been carried out on specimens with different orientations in the temperature range of $700-1000^{\circ} \mathrm{C}$ at different loads to obtain times to rupture up to $35000 \mathrm{~h}$. The comparison of the creep properties with the IN738LC conventionally cast alloy and with the oxide dispersion strengthened MA6000 alloy has shown the better creep performance of the alloy CM247LC DS in the temperature range of interest for application in land based gas turbines.

A series of cyclic load creep tests has allowed to study the effect of load variations on the creep. The effect of cycling stress is to increase the strain rate, compared with the constant load creep tests and then to reduce the rupture life of the alloy.

The LCF tests, performed at the temperatures of $850^{\circ} \mathrm{C}$ and $950^{\circ} \mathrm{C}$ in longitudinal strain controlled conditions, have evidenced a fairly stable cyclic response. Basquin and Coffin-Manson relationships can adequately predict the fatigue life of the alloy.

The CM247LC DS alloy exhibits a better fatigue life than IN738LC and MA6000 alloys.
\end{abstract}

\section{Introduction}

The constant demand of increasing the operating efficiency and durability of land based gas turbines requires the development of alloys with always better mechanical properties at high temperature. Recently, the directional solidification technique has allowed to produce new alloys with excellent high temperature resistance $[1,2]$.

In this investigation the new directionally solidified (DS) nickelbase superalloy CM247LC DS has been studied to evaluate the creep and fatigue properties of the material, to compare its properties with commercial ODS MA6000 and cast IN738LC alloys and to analyse the creep and fatiguc damage mechanisms.

\section{Material characterisation and experimental procedures}

The CM247LC DS alloy is a directionally solidified Ni-base superalloy containing a high volume fraction of the reinforcing $\gamma^{\prime}$ phase. Table I shows the chemical composition of the alloy in $w t \%$.
The alloy was supplied by Howmet in form of directionally solidified slabs with the following dimensions: $\mathrm{L}-160 \mathrm{~mm}$, $\mathrm{W}=100 \mathrm{~mm}, \mathrm{~T}=20 \mathrm{~mm}$.

The alloy microstructure consists of columnar grains with boundaries parallel to the $<001\rangle$ growth direction, with an average width of $0.5 \mathrm{~mm}$ and a grain aspect ratio of about 10. Fig. 1 shows the microstructure $a$ ) in longitudinal (L) and b) in long transverse (LT) direction.

These slabs have received the following solution and $\gamma^{\prime}$ precipitation heat treatment:

$1221^{\circ} \mathrm{C} / 2 \mathrm{~h}+1232^{\circ} \mathrm{C} / 2 \mathrm{~h}+1246^{\circ} \mathrm{C} / 2 \mathrm{~h}+1260^{\circ} \mathrm{C}$ rapid fan quench in argon,

$1079^{\circ} \mathrm{C} / 4 \mathrm{~h}$ rapid fan quench in argon $+871^{\circ} \mathrm{C} / 20 \mathrm{~h}$ rapid fan quench in argon.

The specimens for creep tests under monotonic and cyclic loading had cylindrical symmetry of $5.6 \mathrm{~mm}$ gauge diameter and $28 \mathrm{~mm}$ gauge length. Three thermocouples, tied in the gauge length, allowed to control the temperature gradients $\left(<0.5^{\circ} \mathrm{C}\right)$ during creep. Capacitive transducers, connccted to extensometers clamped to the shoulders of the specimen, continuously monitored the creep strain.

In the cyclic load creep tests, performed on a servo electromechanical machine at $950^{\circ} \mathrm{C}$, the load was cyclically changed between two values. Fig. 2 schematically represents the stress wave form as a function of time.

The low cycle fatigue (LCF) tests were performed in air on a closed loop electro - hydraulic system using cylindrical specimen having $8 \mathrm{~mm}$ gauge diameter and $12 \mathrm{~mm}$ gauge length. An induction coil heated the specimens to the test temperatures of $850^{\circ} \mathrm{C}$ and $950^{\circ} \mathrm{C}$. At $950^{\circ} \mathrm{C}$ both the $\mathrm{L}$ and $\mathrm{LT}$ orientations of the alloy were studied. LCF tests were conducted under longitudinal strain controlled conditions at a constant strain rate of $3 \times 10^{-3} \mathrm{~s}^{-1}$. A fully reversed triangular wave form was used to achieve the various strain amplitudes. During the fatigue tests the stress response and the stress-strain hysteresis loops were recorded at regular intervals.

All the specimen fracture surfaces were examined by scanning electron microscopy (SEM).

Table I - Chemical composition of CM247LC DS alloy, in wt\%.

\begin{tabular}{|c|c|c|c|c|c|c|c|c|c|c|}
\hline $\mathrm{C}$ & $\mathrm{Al}$ & $\mathrm{Co}$ & $\mathrm{Cr}$ & $\mathrm{Mo}$ & $\mathrm{Ta}$ & $\mathrm{Ti}$ & $\mathrm{W}$ & $\mathrm{Nb}$ & $\mathrm{Hf}$ & $\mathrm{Ni}$ \\
\hline 0.07 & 5.55 & 9.5 & 8.1 & 0.5 & 3.2 & 0.69 & 9.5 & 0.05 & 1.4 & $\mathrm{Bal}$. \\
\hline
\end{tabular}



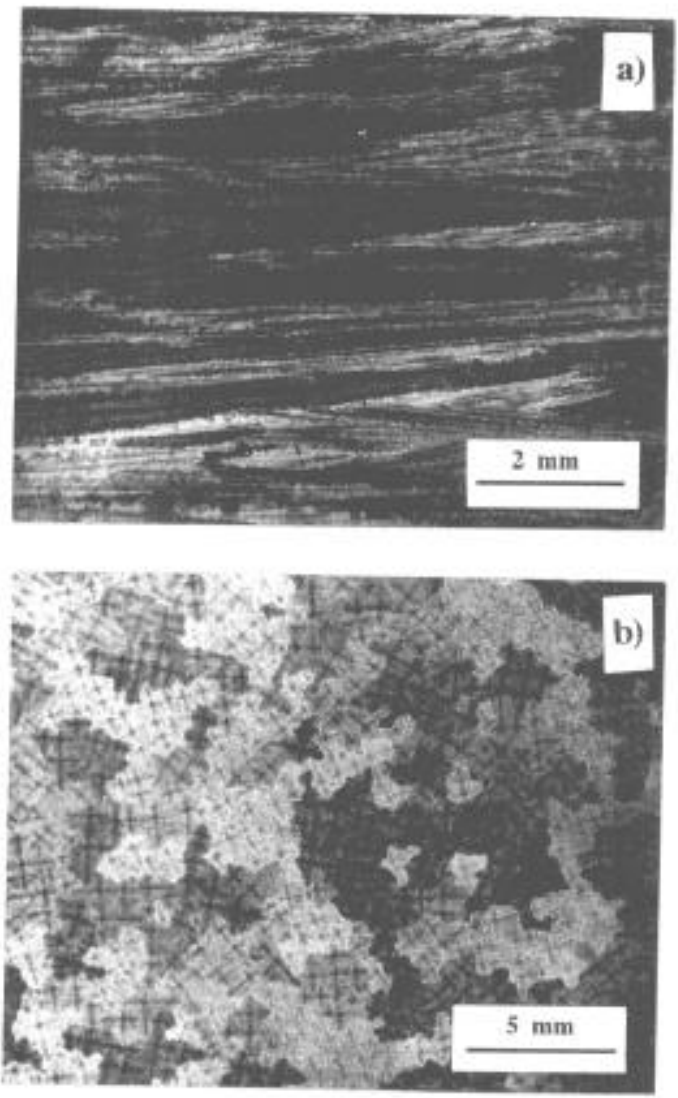

Figure 1 - Microstructure aspect of CM247LC DS alloy in a) L and b) LT direction.

\section{Experimental results and discussion}

\section{Constant load creep results}

Nickel base superalloys often creep with very short primary stage, while the majority of the creep life is tertiary creep. The studied alloy has confirmed this behaviour as shown in Fig. 3, where typical creep curves obtained at different stresses and testing temperatures for the longitudinal orientation are plotted. The primary stage contribution to the creep strain is only important for the tests run at the highest stresses and the lowest temperatures.

As pointed out by different papers $[3,4]$, the dominant tertiary creep in nickel base superalloys, is not associated to fracture mechanisms, but to an increase of the flux of mobile dislocations with the strain due to an increase either of mobile dislocation density or the recovery rate.

A strain rate vs, strain plot (Fig 4) shows that a large portion of the tertiary stage always manifests a linear dependence of the strain rate vs. strain, in agreement with the results obtained on other directionally solidified nickel base superalloys [5]

Fig. 5 shows the stress rupture resistence of CM247LC DS for the $\mathrm{L}$ and LT studied orientations in comparison with the ODS MA6000 with equivalent orientations and with the IN738LC conventionally cast [6-8]. While it is evident the better creep performance of the studied alloy compared with the IN738LC conventionally cast for the stress/temperature explored, the MA6000 alloy shows a better creep resistance at the lowest stresses/highest temperatures for the longitudinal orientation, but a worse behaviour for the transverse orientation

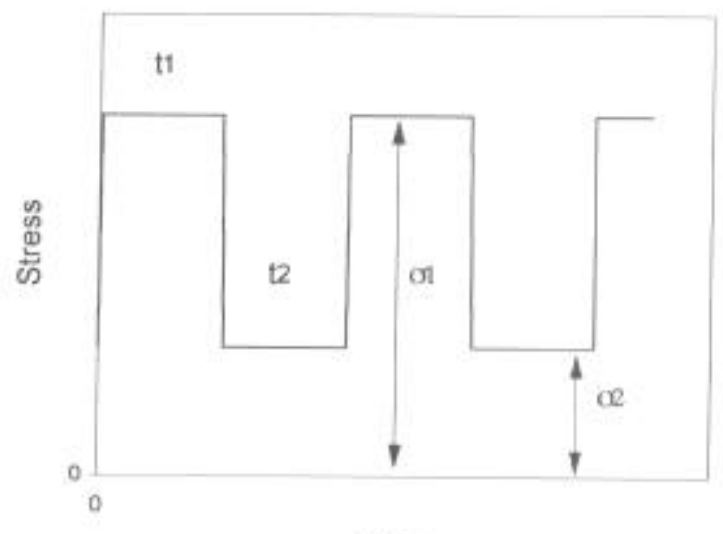

Time

Figure 2 - Stress wave form vs, time

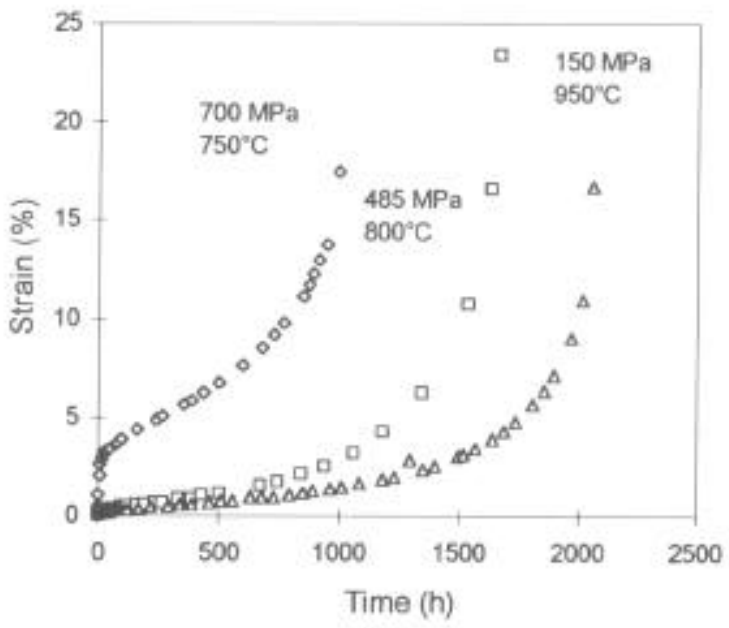

Figure 3 - Creep curves of CM247LC DS at different stresses and temperatures

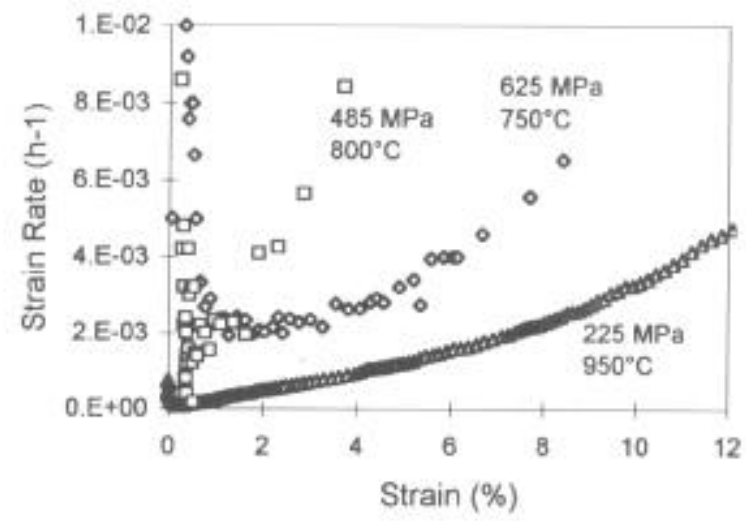

Figure 4 - Strain rate versus strain at different stresses and temperatures in creep tests. 


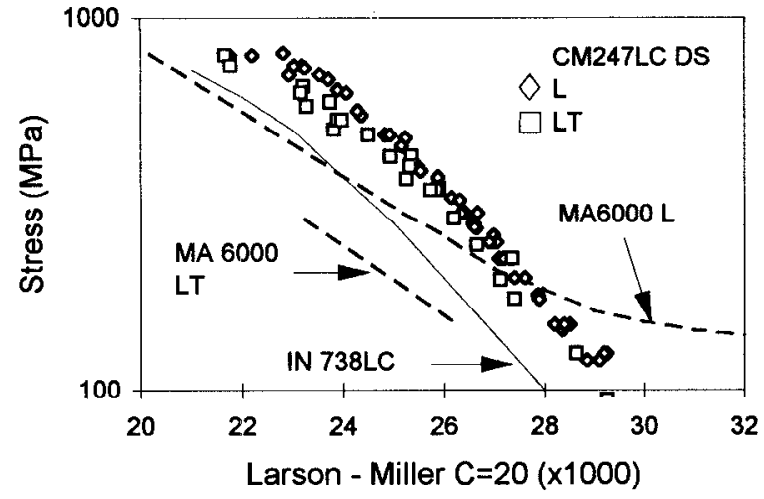

Figure 5 - Comparison of Larson - Miller plots of CM247LC DS, IN738LC and ODS MA6000 alloys.

TABLE II - Rupture data of cyclic creep tests: $\sigma_{1}=225 \mathrm{Mpa}$, $\sigma_{2}=22 \mathrm{Mpa}, \mathrm{T}=950^{\circ} \mathrm{C}$.

\begin{tabular}{|c|c|c|c|c|c|}
\hline $\begin{array}{c}\text { Test } \\
\text { Number }\end{array}$ & $\begin{array}{c}\text { Stress } \\
\text { waveform } \\
\mathrm{t}_{1} \div \mathrm{t}_{2}\end{array}$ & $\begin{array}{c}\varepsilon_{\mathrm{f}} \\
(\%)\end{array}$ & $\begin{array}{c}\text { R.A. } \\
(\%)\end{array}$ & $\begin{array}{c}\text { Rupture } \\
\text { time, } \\
\mathrm{t}_{\mathrm{r}}(\mathrm{h})\end{array}$ & $\begin{array}{c}\text { Total time } \\
\text { on-load }(\mathrm{h})\end{array}$ \\
\hline 1 & $*$ & 26.7 & 54.4 & 172 & 172 \\
2 & $*$ & 43.4 & 61.5 & 168 & 168 \\
3 & $24-0 \mathrm{hr}$ & 29.0 & 55.6 & 141 & 141 \\
4 & $1-0 \mathrm{hr}$ & 23.7 & 56.0 & 143 & 140 \\
5 & $1-1 \mathrm{hr}$ & 31.0 & 62.2 & 203 & 102 \\
6 & $30-30 \mathrm{~min}$ & 20.0 & 52.0 & 232 & 116 \\
7 & $5-5 \mathrm{~min}$ & 19.7 & 57.0 & 232 & 116 \\
8 & $24-24 \mathrm{hr}$ & 28.8 & 62.3 & 253 & 136 \\
9 & $30-5 \mathrm{~min}$ & 24.0 & 60.0 & 176 & 152 \\
\hline
\end{tabular}

* Constant load creep tests $\left(\sigma=225 \mathrm{MPa}, \mathrm{T}=950^{\circ} \mathrm{C}\right)$.

\section{Cyclic load creep results}

All the cyclic creep tests have been performed at $950^{\circ} \mathrm{C}$ on specimens with $\mathrm{L}$ orientation. Most of these tests have been run at a maximum and minimum stress of $225 \mathrm{MPa}$ and $22 \mathrm{MPa}$ respectively, with different hold times at the highest and lowest stress. The minimum load of $22 \mathrm{MPa}$ was imposed to kecp the specimen in alignment and no creep was expected to occur during this load level. The loading and unloading time was about one minute. Table II shows the details of the experimental results.

Fig. 6 shows the variation of creep strain with elapsed time for the tesis of Table II.

We can observe that the cyclic stressing decreases the rupture life of the alloy and the rupture properties, even in the tests without hold time at lowest stress. In addition both the unloading hold time and the number of unloading and reloading are important to determine the time to rupture.

The ductility of the alloy, in terms of reduction of area and fracture strain, remains unaffected by the different loading conditions.

The effect of the off-load period is to produce a creep rate acceleration in the following on-load period as evident in Fig. 7 that shows the strain rate behaviour during on-load period in the cyclic creep tests 3 and 8 of Table II compared with two constant
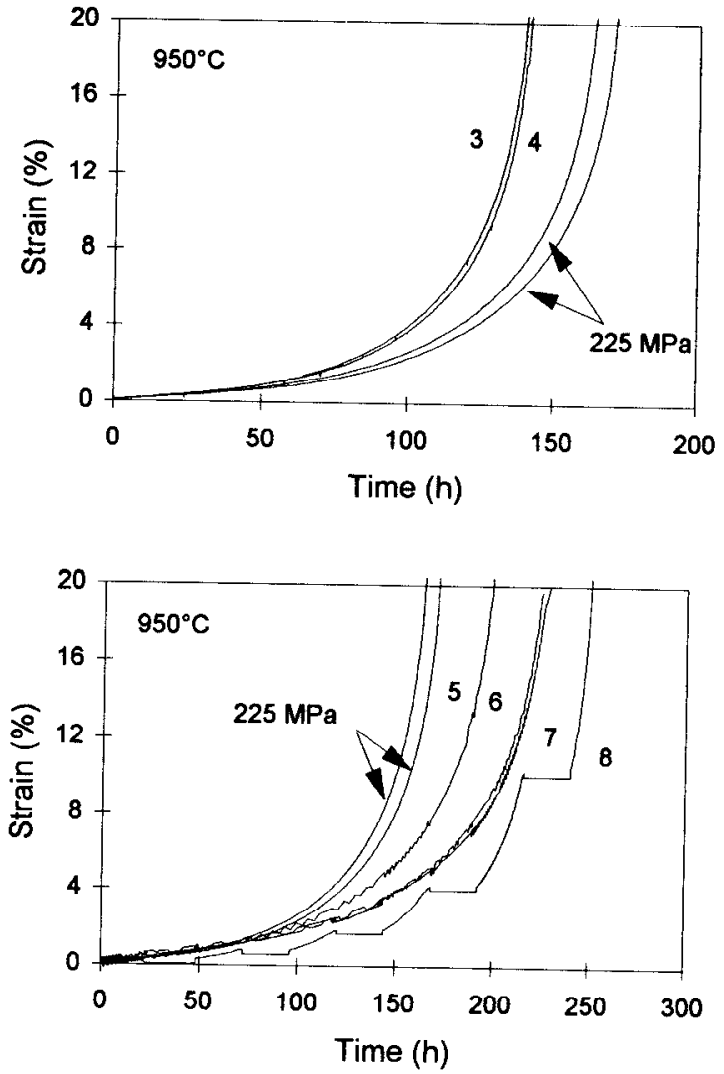

Figure 6 - Comparison between constant load creep tests at $225 \mathrm{MPa}$ and the cyclic creep tests of Table II.

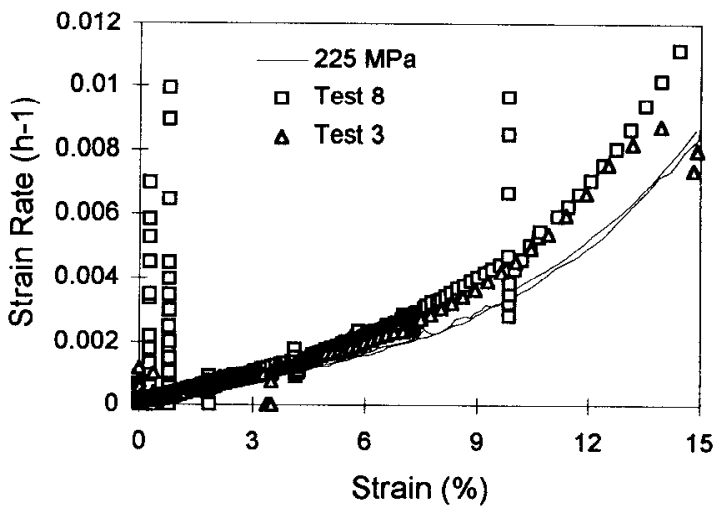

Figure 7 - Comparison of the strain rate vs strain for the cyclic creep tests number 3 and 8 of Table II and two constant load creep tests at $225 \mathrm{MPa}$

creep tests at $225 \mathrm{MPa}$. Both cyclic creep tests show a higher creep strain rate compared with the constant load tests. For test 8 , on each reloading, the strain rate quickly decreases from a high value to a minimum which is observed to be less than that obtained under constant load creep and then it increases gradually up to overtake the strain rate measured in the constant load creep tests. Additional work is needed to rationalise the observed experimental results. 
TABLE III - Rupture data for stress cycling between two stress levels

\begin{tabular}{|c|c|c|c|c|}
\hline $\begin{array}{c}\text { Stress wave } \\
\text { form }\end{array}$ & $\begin{array}{c}\text { Strain to } \\
\text { rupture, } \varepsilon_{\mathrm{f}}(\%)\end{array}$ & $\begin{array}{c}\text { Reduction of } \\
\text { Area, R.A. (\%) }\end{array}$ & $\begin{array}{c}\text { Rupture time, } \\
\mathrm{t}_{\mathrm{r}}(\mathrm{h})\end{array}$ & $\begin{array}{c}\text { Linear } \\
\text { Fraction Rule }\end{array}$ \\
\hline $\begin{array}{c}300 \mathrm{MPa}-4 \mathrm{~h} \\
175 \mathrm{MPa}-68 \mathrm{~h}\end{array}$ & 29.0 & 56.0 & 158.0 & 0.57 \\
\hline $\begin{array}{c}300 \mathrm{MPa}-4 \mathrm{~h} \\
225 \mathrm{MPa}-20 \mathrm{~h}\end{array}$ & 30.3 & 53.7 & 88.5 & 0.88 \\
\hline $\begin{array}{c}300 \mathrm{MPa}-4 \mathrm{~h} \\
250 \mathrm{MPa}-10 \mathrm{~h}\end{array}$ & 24.4 & 61.8 & 44.0 & 0.71 \\
\hline
\end{tabular}

Few specimens were tested in cyclic creep between a higher stress, $\sigma_{1}=300 \mathrm{MPa}$, with a hold time, $\mathrm{t}_{1}$ and a lower stress $\sigma_{2}$ ranging between 175 and $250 \mathrm{MPa}$ with a hold time $t_{2}$. The holding times $t_{1}$ and $t_{2}$ are approximately $10 \%$ of the rupture life under constant load creep tests for the respective stress levels. The results are summarised in Table III for different values of minimum loads. The value of the constant of the Robinson's Life Fraction Rule is also shown: at the rupture, the sum of the creep life fractions consumed at each load condition always results in a value less than unity.

A typical creep curve for $\sigma_{1}=300 \mathrm{MPa}\left(\mathrm{t}_{1}=4 \mathrm{hrs}\right)$ and $\sigma_{2}=225$ $\mathrm{MPa}\left(\mathrm{t}_{2}=20 \mathrm{hrs}\right)$ is presented in Fig. 8 in form of the strain rate against strain. Similar data, under constant creep loading at 300 $\mathrm{MPa}$ and $225 \mathrm{MPa}$, are also included for comparison.

On reducing the stress from $300 \mathrm{MPa}$ to $225 \mathrm{MPa}$, the transient creep is characterised by a strain rate decreasing down to a minimum value, after that it starts an increase staying always below the curve of the constant load creep test. A similar type of transient has been reported previously both in pure metals and solid solutions [9] and recently in Ni-base superalloys [10].

After reloading the specimen, the strain rate quickly decreases from a high value to a minimum followed by a rapid increase in the strain rate. At the end of the transient the strain rate stays above the constant load creep curve.

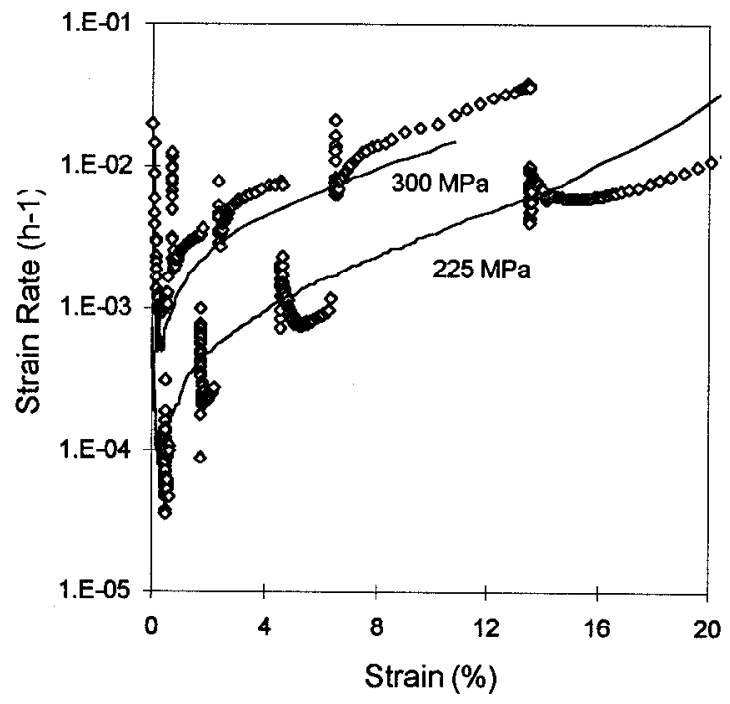

Figure 8 - Strain rate versus strain for cyclic stressing between $300 \mathrm{MPa}$ and $225 \mathrm{MPa}$ (Table III) in comparison with constant load creep tests at $300 \mathrm{MPa}$ and $225 \mathrm{MPa}$ (lines).

\section{Low Cycle Fatigue}

In the strain controlled LCF tests the cyclic stress response curves represent the variation of the stress amplitude versus the progressive number of cycles. The stress range levels were almost constant through the test with only approximate $3 \%$ softening until close to failure.

The variation of the stress amplitude with the plastic strain is established to determine the cyclic stress-strain curves and the data are represented by Hollomon type equation of the form:

$$
\frac{\Delta \sigma_{\mathrm{a}}}{2}=\mathrm{K} *\left(\frac{\Delta \varepsilon_{\mathrm{p}}}{2}\right)^{\mathrm{m}}
$$

where $\Delta \sigma_{\mathrm{a}}$ is the stress amplitude, $\Delta \varepsilon_{\mathrm{p}}$ the plastic strain component, $\mathrm{K}$ the cyclic strength coefficient and $\mathrm{m}$ the cyclic strain exponent. The parameters are determined by least square method and listed in Table IV. The table also contains the fracture strain and the ultimate tensile strength (UTS) under monotonic loading. The values of $\mathrm{K}$ scale with those of the UTS. It is noteworthy that the value of the cyclic strain exponent is about 0.2 , independent of the test temperature and the direction of the loading axis with respect to the columnar grain orientation.

The number of cycles to failure, $\mathrm{N}$, has been defined in the point where the rapid variation of the stress level in the $\Delta \sigma-n$ curve occurs. This variation corresponds to a crack length from 0.5 to $1 \mathrm{~mm}$ depending on the total strain imposed. Fig. 9 shows the influence of test temperature and specimen grain orientations on the fatigue life of CM247LC DS alloy. A fatigue life decrease is observed when temperature increases and when the material is tested in LT direction. For the same imposed strain range, the fatigue life in $\mathrm{L}$ direction is from 6 to 7 times longer than in LT direction. The results can be partially explained by the higher Young modulus, E, for the material in the LT direction (Table IV). Fig. 10 shows the elastic and plastic strain components at half life versus the number of cycles to failure (N) at $850^{\circ} \mathrm{C}$ and $950^{\circ} \mathrm{C}$. On the basis of the elastic strain-life data, the fatigue resistence at $850^{\circ} \mathrm{C}$ is superior to that at $950^{\circ} \mathrm{C}$, whereas the reverse seems to be the case when comparing the plastic strain-life curves.

Table IV - Cyclic stress-strain parameters and tensile properties.

\begin{tabular}{|c|c|c|c|c|c|c|}
\hline $\begin{array}{c}\text { Temp. } \\
{ }^{\circ} \mathrm{C}\end{array}$ & $\begin{array}{c}\text { Grain } \\
\text { orient. }\end{array}$ & $\begin{array}{c}\text { Tensile fracture } \\
\text { strain, } \mathrm{mm} / \mathrm{mm}\end{array}$ & $\begin{array}{c}\text { UTS } \\
\mathrm{MPa}\end{array}$ & $\begin{array}{c}\mathrm{K} \\
\mathrm{MPa}\end{array}$ & $\mathrm{m}$ & $\begin{array}{c}\mathrm{E} \\
\mathrm{GPa}\end{array}$ \\
\hline 850 & $\mathrm{~L}$ & 0.207 & 965 & 1127.2 & 0.217 & 90.6 \\
950 & $\mathrm{~L}$ & 0.356 & 740 & 692 & 0.195 & 84.3 \\
950 & $\mathrm{LT}$ & 0.118 & 680 & 680.4 & 0.207 & 106.5 \\
\hline
\end{tabular}




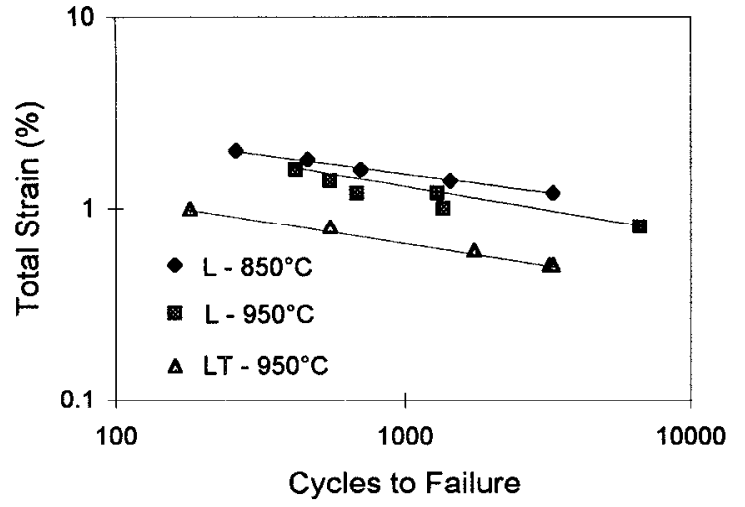

Figure 9 - Total strain range versus the number of cycle to failure.

However, the plastic strain-life curve presents some scatters at the lower imposed strain ranges.

The fatigue life of the alloy can be described by the empirical relationships of Basquin [11] and Coffin-Manson [12] respectively as follows:

$$
\begin{aligned}
& \frac{\Delta \varepsilon_{\mathrm{e}}}{2}=\frac{\sigma_{\mathrm{f}}}{E}(\mathrm{~N})^{-\mathrm{b}} \\
& \frac{\Delta \varepsilon_{\mathrm{p}}}{2}=\varepsilon_{\mathrm{f}}(\mathrm{N})^{-\mathrm{c}}
\end{aligned}
$$

where $\sigma_{f}$ and $b$ are the fatigue strength coefficient and fatigue strength exponent respectively, while $\varepsilon_{\mathrm{f}}$ and $c$ are the failure ductility coefficient and fatigue ductility exponent respectively. The values of these parameters are listed in Table $\mathrm{V}$.

It should also be noted that a better correlation is obtained for the elastic strain-life data. The relationships between the elastic, plastic strain components and the number of cycles to failure are also obtained by using equations 2 and 3 .

The fatigue resistance of the directionally solidified CM247LC DS is compared at $850^{\circ} \mathrm{C}$ and $950^{\circ} \mathrm{C}$ (Fig. 11), on the total strain-life basis, with ODS MA6000 and IN738 LC conventionally cast alloys which are designed for similar applications. CM247LC DS exhibits superior fatigue resistance than that of other alloys in the whole testing temperature rangc. A similar behaviour was found by Vasser and Remy [13].

Table V - Fatigue parameters of Basquin and Coffin-Manson relationships.

\begin{tabular}{|c|c|c|c|c|c|}
\hline $\begin{array}{c}\text { Temperature } \\
{ }^{\circ} \mathrm{C}\end{array}$ & $\begin{array}{c}\text { Grain } \\
\text { orientation }\end{array}$ & $\begin{array}{c}\sigma_{\mathrm{f}} \\
\mathrm{GPa}\end{array}$ & $\mathrm{b}$ & $\begin{array}{c}\boldsymbol{\varepsilon}_{\mathrm{f}} \\
\mathrm{mm} / \mathrm{mm}\end{array}$ & $\mathrm{c}$ \\
\hline 850 & $\mathrm{~L}$ & 176 & 0.15 & 0.075 & 0.68 \\
950 & $\mathbf{L}$ & 140.7 & 0.17 & 0.13 & 0.75 \\
950 & $\mathrm{LT}$ & 99 & 0.17 & 0.048 & 0.69 \\
\hline
\end{tabular}

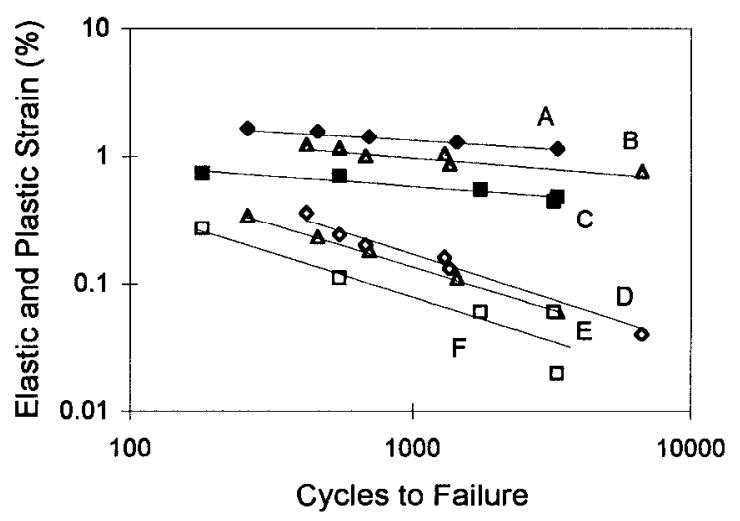

Figure 10 - Plastic and elastic strain components versus the number of cycles to failure: $\mathrm{A}=\Delta \varepsilon_{\mathrm{e}}, \mathrm{L}-850^{\circ} \mathrm{C} ; \mathrm{B}=\Delta \varepsilon_{\mathrm{e}}, \mathrm{L}-950^{\circ} \mathrm{C} ; \mathrm{C}=\Delta \varepsilon_{\mathrm{e}}$, LT- $950^{\circ} \mathrm{C} ; \quad \mathrm{D}=\Delta \varepsilon_{\mathrm{p}}, \mathrm{L}-950^{\circ} \mathrm{C} ; \quad \mathrm{E}=\Delta \varepsilon_{\mathrm{p}}, \mathrm{L}-850^{\circ} \mathrm{C} ; \quad \mathrm{F}=\Delta \varepsilon_{\mathrm{p}}$, LT $-950^{\circ} \mathrm{C}$.

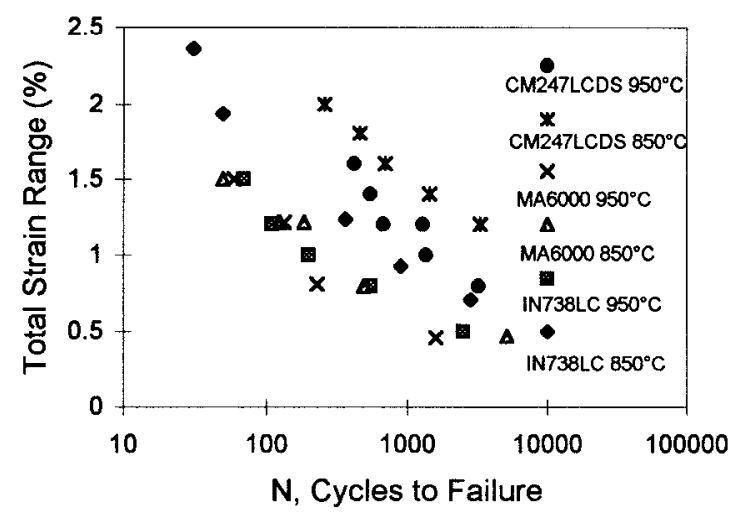

Figure 11 - Comparison of faigue life of CM247LC DS with MA6000 and IN738LC alloys.

\section{Metallography}

A typical creep fracture surface obtained on longitudinal stressed specimen is shown in Fig. 12. The presence of crystallographic facets associated with casting pores, suggests that the fracture originates from pores and then propagates on (001) planes. Examples of such pores are shown in Fig. 13 as observed from the longitudinal section of the specimen. Cracks propagating from the surface of the pores are also visible.

Some of these cracks were also observed to be initiated due to decohesion at carbide and matrix interface or due to carbide fracture, as illustrated in Fig. 14.

The observed fracture process, as it should be expected, agrees with the results on single crystals of Ni-base superalloys [14].

The fatigue failure mechanisms in Ni-base superalloys involve crack initiation at near surface flaws. Attempts were therefore made to detect some of the features that are often associated with fatigue failure. The SEM micrograph in Fig. 15 shows the fracture surface of a specimen tested at $850^{\circ} \mathrm{C}$ with a total imposed strain range of $1.2 \%$. The micrograph shows a micropore at the 
specimen surface that could act as a zone of stress concentration and eventually as the site of fatigue crack initiation. The pores could also act as origin of fatigue crack initiation, as it seems to be indicated by the SEM micrograph in Fig. 16 for the L specimen fatigued at $850^{\circ} \mathrm{C}$ under an imposed total strain range of $1.6 \%$. No slip off-sets were discernible on the specimen surface.

Fatigue striations are occasionally observed and secondary cracks are frequently found in L direction specimens as shown by SEM micrograph in Fig. 17, Also in LT specimens transgranular crack propagation and secondary crack are observed.

The fracture aspect and the occurrence of secondary cracks depend on the amount of the imposed strain range. At lower imposed strain range, i.e. $\Delta \varepsilon_{\mathrm{t}}=0.5 \%$, no secondary cracks are observed and the fracture surface is macroscopically flat. At higher strain ranges, fatigue striations are also observed with numerous secondary cracks

The fatigue crack initiation phase consists of cracking along the crystallographic direction inclined to the applied load, i.e. stage I type and a typical example of initiation zone is shown in Fig 18. The subsequent crack growth direction is perpendicular to the applied load (stage II type)

The fatigue failure mechanism can thus be envisaged as follows: crack initiates along the slip bands that intersect the defects e.g. pores on the specimen surface; although the precise role of oxygen can not be specified, the diffusion of this element along the deformed zone could also facilitate shear decohesion while the pore induces a local stress concentration. Once the crack is formed, its subsequent growth direction is perpendicular to the applied load.

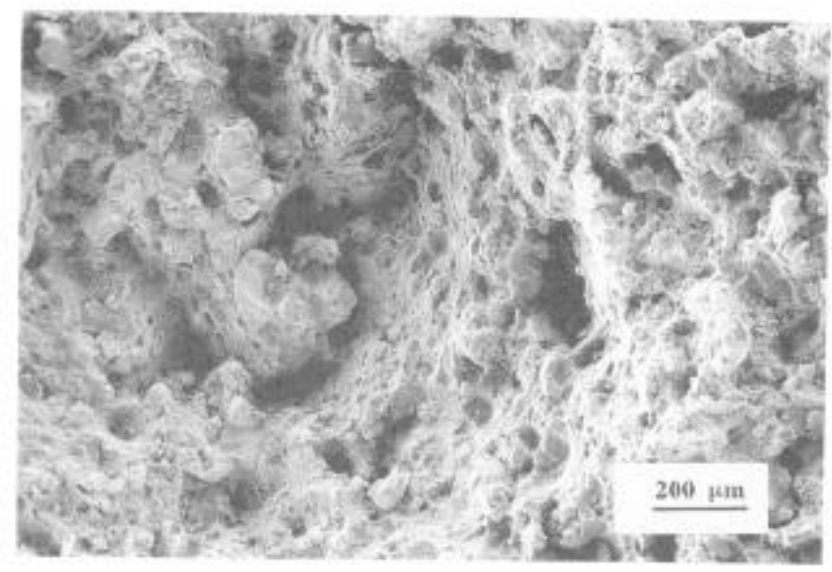

Figure 12 - Typical fracture surface showing the presence of holes as sites for microcrack initiation.

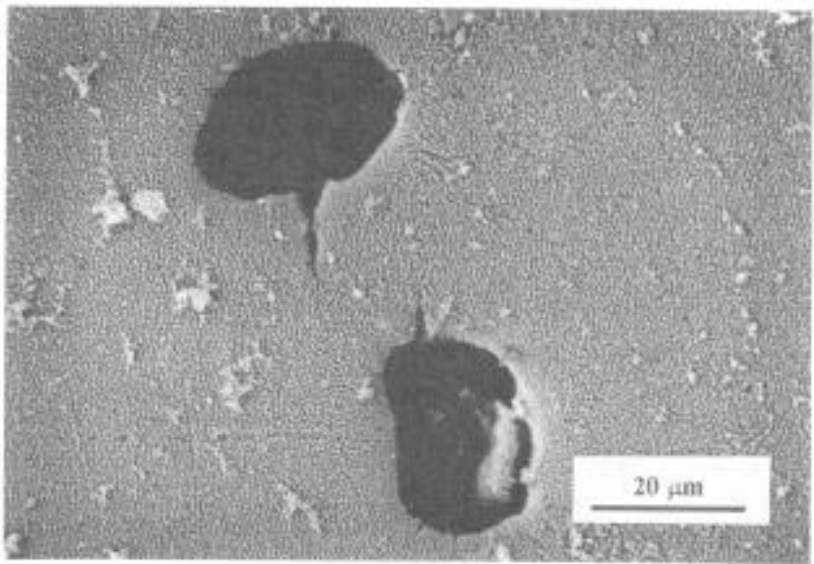

Figure 13 - Pores as observed on longitudinal section by SEM

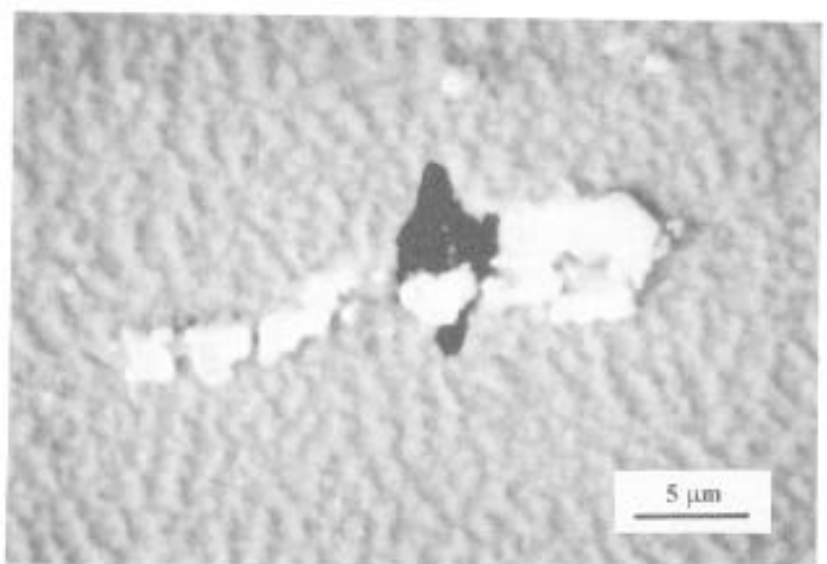

Figure 14 - Microcrack formation at carbide sites by SEM 


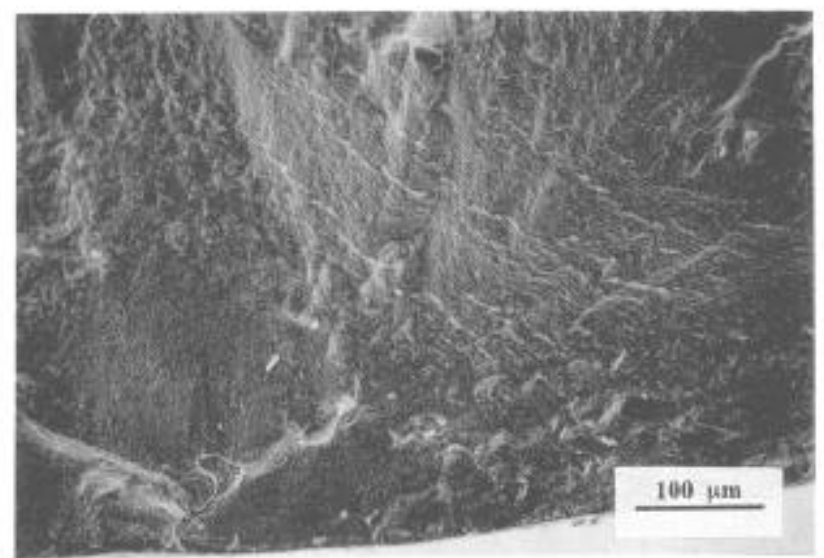

Figure 15 - Aspect of fatigue fracture: crack initiation at surface pore; $\mathrm{L}-850^{\circ} \mathrm{C}, \Delta \varepsilon_{\mathrm{t}}=1.2 \%, \mathrm{~N}=3300$.

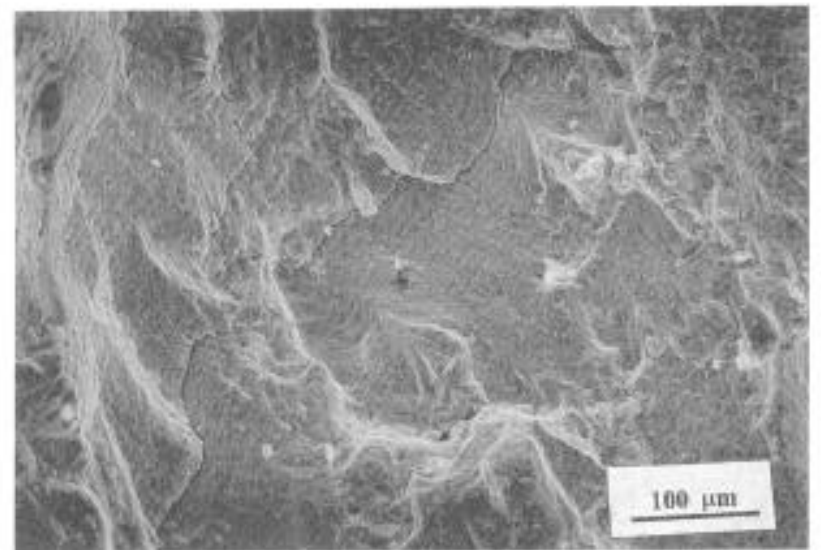

Figure 17 - Presence of fatigue striations and secondary cracks: L. $950^{\circ} \mathrm{C}, \Delta \varepsilon_{1}=1.6 \%, \mathrm{~N}=420$

\section{Conclusions}

The alloy CM247LC DS possesses a clear cut advantage, in creep properties, over that of IN738LC conventionally cast and MA6000 alloys.

After a step like load increase or decrease, the strain rate stabilises respectively to a higher or lower value, if compared with the constant load creep tests.

Irrespective of the cyclic stress wave form imposed on the alloy, a strain rate acceleration is always observed during on-load periods if constant load creep test is taken as a reference. Such strain rate acceleration could be an important factor to be taken into account when modelling the behaviour of the alloy under variable loading Creep fractures show that microcracks initiate at the shrinkage pores and at carbides and matrix interface.

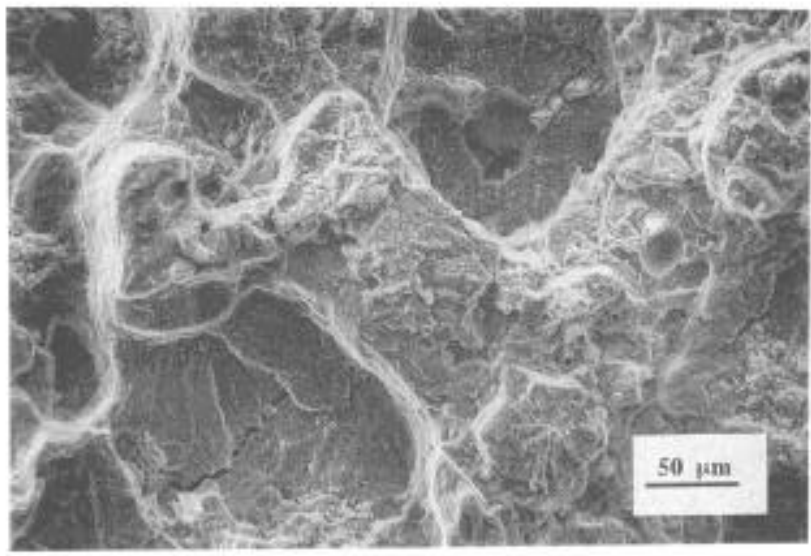

Figure 16- Presence of some pores in the interior of the specimen: L $-850^{\circ} \mathrm{C}, \Delta \varepsilon_{1}=1.6 \%, \mathrm{~N}=700$

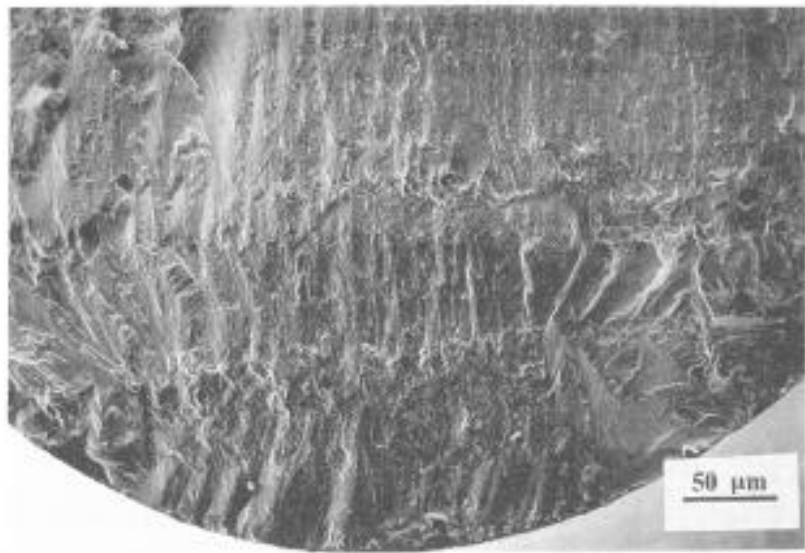

Figure 18 - Exemple of crack initiation zone LT- $950^{\circ} \mathrm{C}$, $\Delta \varepsilon_{1}=0.5 \%, N=3300$.

In strain control LCF tests, the alloy exhibits fairly stable cyclic stress response, with only a slight stress softening. The fatigue life of the alloy can be satisfactorily predicted by the empirical relationships of Coffin-Manson and Basquin with the latter giving a better correlation

The fatigue ductility parameters obtained from these relationships and the tensile properties of the alloy give reasonable correlation. The fatigue crack initiation is mainly due to the shrinkage pores located at the surface or sub-surface of the specimen.

The alloy exhibits superior fatigue resistance than that of ODS MA6000 and IN738LC Ni-base superalloys 
Acknoledgements The authors would like to acknowledge the skilful technical assistance of Mr. Bianchessi, Mr. E. Picco, Mr. D. Ranucci and Mr. E. Signorelli. G. A. Osinkolu undertook this work with the support of "ICTP Programme for Training and Research in Italian Laboratories", Trieste, Italy. The work was partially performed in the European programme COST 501 Second Round.

\section{REFERENCES}

1. M. McLean, Directionally Solidified Materials for High ITemperature Service (London: The Metals Society, 1983).

2. K. Schneider, Iligh Temperatue Materials for Power Engineering, (Dordrecht, Netherland: Kluver Academic Publishers, 1994), 1155-1164.

3. B.F. Dyson and M. McLean, "Particle-Coarsening, $\sigma_{0}$ and Tertiary Creep", Acta Metall., 31 (1983) 17-27.

4. A. Barbosa et al., Superalloys 1988 (Warrendale, PA:The Metallurgical Society, 1988), 683-692.

5. M. Maldini and V. Lupinc, "A Representation of Tertiary Creep Behaviour in a Single Crystal Nickel-Based Superalloy", Scripta Metall, 22 (1988), 1737-1741.

6. R.C. Benn and S.K. Kang, Superalloys 1984 (Warrendale, PA:The Metallurgical Society, 1984), 319-326.

7. E. Arzt and R. Timmins, Creep Properties of ODS Superalloys, A Summury of Results Obtained by the ODS Group in Cost 501, Petten, Netherland: Commission of The European Communities Institute of Advanced Materials Joint Research Centre Petten, 1991).

8. V. Lupinc et al., "Nuove superleghe a struttura direzionale per palette di turbine agas avanzate", La Metallurgia Italiana, 81 (1989), 825-834.

9. M. Biberger and J.C. Gibeling, "Analysis of Creep Transients in Pure Metals Following Stres Changes", Acta Metall. Mater., 43 (1995) 3247-3260.

10. M. Maldini, CREEP: Characterization, Damage and Life Assessment (Materials Park, Ohio:ASM International, 1992), 111116.

11. O.H. Basquin, "The experimental law of endurance tests", ASTM 10, (1910) 610-625.

12. L.F. Jr. Coffin, "Fatigue at high temperature", Fatigue at Elevated Temperatures ASTM STP 520, (1972) 520,5-34.

13. E. Vasseur, and L. Rémy, "High temperature low cycle fatigue and thermal-mechanical fatigue behaviour of on oxide-dispersion strengthened nickel-base superalloy", Mater. Sci. and Eng., A184 (1994) 1 - 15.

14. S. H. Ai, V. Lupinc, and M. Maldini, "Creep Fracture Mechanisms in Single Crystal Superalloys", Scripta Metall. Mater., 26 (1992) 579-584. 